\section{A Preliminary Study of Extraction and Characterization of Nanocrystalline Cellulose (NCC) from Ramie Fiber}

\section{Kusmono* \\ M.W. Wildan \\ M.N. Ilman}

Department of Mechanical and Industrial Engineering, Faculty of Engineering, Universitas Gadjah Mada. Jl. Grafika 2, Yogyakarta 55281, Indonesia

Email:

*kusmono@ugm.ac.id

\section{Keywords}

nanocrystalline cellulose, ramie fiber, chemical treatment, crystallinity index, thermal stability.

\begin{abstract}
Nanocrystalline cellulose (NCC) is today's one of rapidly growing nanocomposite reinforcing materials. This is thanks to some advantages that come with it over anorganic nanocomposite reinforcing materials, for example, nanoclay, nanosilica, nanoalumina, carbon nanotubes, among others. Some of the advantages of NCC are environment-friendliness due to being organic-compound-based, high mechanical property, and easy manufacturing. NCC can be extracted from natural cellulose sources, such as natural fiber, wood, and animals. One of the natural fibers rich in cellulose content, in this case around $80 \%$, is fiber of ramie which is ubiquitous in Indonesia. It is well known that the acid hydrolysis method is an easy route to NCC fabrication. A number of chemical treatments like de-waxing, bleaching, and alkaline treatment are typically performed prior to acid hydrolysis process. The effect of such chemical treatments as precursors of alkaline hydrolysis on ramie fiber characteristics was investigated in this research. Firstly, ramie fiber was cut $1 \mathrm{~cm}$ in size, then grinded and sieved. The fiber was then subjected to de-waxing process by adding it into a toluene-ethanol solution (1:2). Then, it was submitted to bleaching with $0.7 \%$ sodium chlorite $(\mathrm{NaClO} 2)$ solution at $75^{\circ} \mathrm{C}$ for 1 hour. Lastly, the fiber was subjected to an alkaline treatment in $2 \% \mathrm{NaOH}$ solution for 2 hours. Characterization with FT-IR, XRD, and TGA of the fiber which had underwent a number of surface treatments was conducted. Results show that the chemical treatments had successfully removed amorphous components like lignin and hemicellulose from the ramie fiber. Chemical treatments were proven able to increase the crystallinity index and thermal stability of ramie fiber.
\end{abstract}




\section{Introduction}

Nanocrystalline cellulose (NCC) is a nano-scale, needle-like cellulose material 5-10 $\mathrm{nm}$ in diameter and $100-500 \mathrm{~nm}$ in length which is synthesized from a cellulose source (Kian et al., 2018). NCC is a promising organic nanoparticle material with several unique properties, including nano-scale size, high specific strength and modulus, high surface area, high crystallinity and unique optical properties, high crystallinity index, ultra light weight, and environment-friendliness (Csiszar et al., 2016; Ngwabebhoh et al., 2018). The NCC material has a range of potential applications in various fields, for example, medical, optical, and nanocomposite material applications (Li et al., 2012).

The acid hydrolysis method is the most widely used natural-cellulose-based NCC manufacturing method (Habibi et al., 2010). Included in natural celluloses are natural and marine animal fibers. Sulfuric acid at a concentration of $60-70 \%$ and temperature of $45^{\circ} \mathrm{C}$ and hydrolysis time of around few minutes up to several hours have also been frequently used in acid hydrolysis processes (Jonoobi et al., 2015). Acid hydrolysis can remove amorphous components (e.g., wax film, hemicellulose, lignin) from natural fibers.

Ramie fiber is a natural fiber derived from ramie plants abundant in Indonesia. It contains relatively high cellulose (80-85 wt \%) and high mechanical property. By far, ramie fiber applications are still confined to rod materials, gunny sacks, fabric or paper materials, and microcomposite reinforcement. Thus, it is of considerable interest if a research study is performed on NCC fabrication from high-cellulose ramie fiber. NCC extraction and characterization studies have been performed by some previous researchers using a variety of natural cellulose sources, for example, bamboo (Brito et al., 2012), straw (Lu and Hsieh, 2012), palm tree (Ilyas et al., 2018), and so forth. Ramie-sourced NCC extraction and characterization research is still rare, leading to the need for conducting a study on NCC fabrication from ramie fiber.
Before acid hydrlysis process, some chemical treatments for ramie fiber purification like de-waxing, bleaching, and alkiline treatment were carried out. The results of the ramie fiber characterization past the chemical treatments (de-waxing, bleaching, alkali) are reported in this paper. The characterization was conducted with FT-IR, $\mathrm{XRD}$, and TGA.

\section{Methodology}

Ramie fiber was cut $1 \mathrm{~cm}$ in size, grinded, and sieved to pass 40 mesh. Then, the fiber was de-waxed in a solution of a mixture of toluene and ethanol (2:1) using Soxhlet. Afterwards, the fiber was washed in alcohol and water, then dried at $80^{\circ} \mathrm{C}$ for 2 hours.

In the next step, the fiber was bleached at $75{ }^{\circ} \mathrm{C}$ for 1 hour in a $0.7 \%$ sodium chlorite $(\mathrm{NaClO} 2)$ solution and added with acetic acid until $\mathrm{pH}$ 4. The fiber-to-solution ratio was 1:100 $(\mathrm{w} / \mathrm{v})$. The fiber then rinsed in distilled water until the $\mathrm{pH}$ became normal and oven-dried at $80{ }^{\circ} \mathrm{C}$ for 2 hours. The bleaching result was submitted to alkalization with $2 \% \mathrm{NaOH}$ solution at $95^{\circ} \mathrm{C}$ for 2 hours, then rinsed and dried. Afterwards, the ramie fiber was subjected to characterization using FT-IR, XRD, and TGA. In addition, the untreated ramie fiber chemical composition was also tested using standard gravimetry.

\section{Results and Discussion}

From the untreated ramie fiber chemical composition test, it was found that the ramie fiber contained $86.38 \%$ holocellulose, $72.68 \% \alpha$-cellulose, and $0.48 \%$ lignin, indicating that ramie fiber does contain very high cellulose and low lignin. From the results, it can be concluded that the rich cellulose content in ramie fiber causes it to be highly crystalline. Thus, the potential for nanocrystalline cellulose (NCC) manufacturing from ramie fiber cellulose source is enormous.

Figure 1 shows the FT-IR spectra for the fiber before and after de-waxing, bleaching, and alkaline treatment. The figure reveals that the ramie fiber both before and 
after chemical treatments had the same peaks: $3,464 \mathrm{~cm}^{-1} ; 2,931 \mathrm{~cm}^{-1} ; 2,368 \mathrm{~cm}^{-1} ; 1,751 \mathrm{~cm}^{-1}$; $1,643 \mathrm{~cm}^{-1}$; and $1,064 \mathrm{~cm}^{-1}$. The peak 3,464 $\mathrm{cm}^{-1}$ shows the characteristic of the hydroxyl group $-\mathrm{OH}$ in cellulose, hemicellulose, and lignin. The peak $2,931 \mathrm{~cm}^{\circ 0_{-}}$shows the characteristic of the methyl and methylen of $\mathrm{C}-\mathrm{H}$ stretching. The peak $2,368 \mathrm{~cm}^{-1}$ indicates the acetyl group of $\mathrm{C}-\mathrm{O}$ stretching, while the peak $1,751 \mathrm{~cm}^{-1}$ the carboxylic group $\mathrm{C}=\mathrm{O}$ in hemicellulose and pectin. The peak 1,643 cm1 indicates the $\mathrm{C}=\mathrm{C}$ group in lignin. The peak $1,435 \mathrm{~cm}^{-1}$ indicates the characteristic of the $\mathrm{CH} 3$ group, while the peak 1,064 $\mathrm{cm}^{-1}$ shows the acetyl group $\mathrm{C}-\mathrm{O}$ in lignin. The FT-IR results also show that the peak $1,751 \mathrm{~cm}^{-1}$ which is characteristic of the $\mathrm{C}=\mathrm{O}$ group in hemicellulose and pectin in untreated ramie fiber did not show up after de-waxing, bleaching, and alkaline treatments. It can be concluded that surface chemical treatments had successfully solved the amorphous components in fiber like wax, hemicellulose, and pectin.

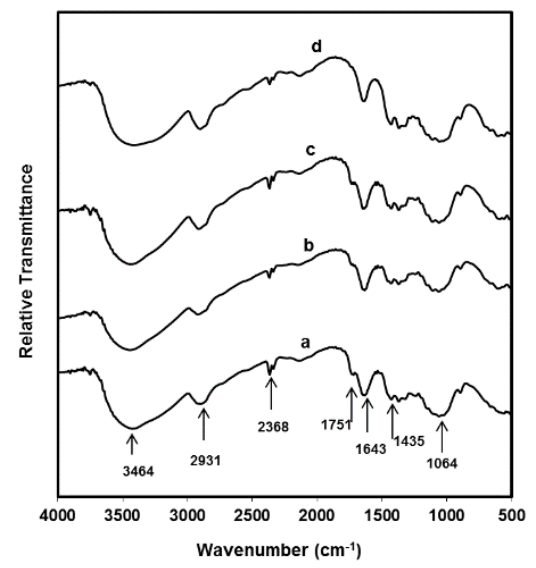

Figure 1. FT-IR of ramie fiber powder: a.untreated; b. de-waxing; c. Bleaching; d. Alkali

The CRD patterns of ramie fiber before and after chemical treatments are presented in Figure 2. It can be seen that three samples (before, after alkaline treatment, and after Soxhlet treatment) exhibited 3 same peaks, namely about $2 \theta=18,22$, and $35^{\circ}$. All the peaks show the crystalline structure of cellulose 1 , which were determined as crystal fields $(10 \overline{\mathrm{I}}),(002)$, and (040). Then, from the
XRD patterns, the crystallinity index was calculated by referring to Segal's equation (Segal et al., 1959), and the results are recorded in Table 1. The crystallinity index of the fiber before treatment was $79.75 \%$, after de-waxing $85.63 \%$, after bleaching $85.50 \%$, and after alkaline treatment $86.68 \%$. From these results, it can be concluded that chemical treatments (de-waxing, bleaching, and alkali) had increased the crystallinity index of the ramie fiber. The crystallinity index rise is related to the dissolution of some amorphous components like hemicellulose, lignin, pectin, and wax film and to the readjustment of the crystal area. De-waxing is a treatment for removing the wax film in ramie fiber, bleaching for lignin, and alkaline treatment for hemicellulose component.

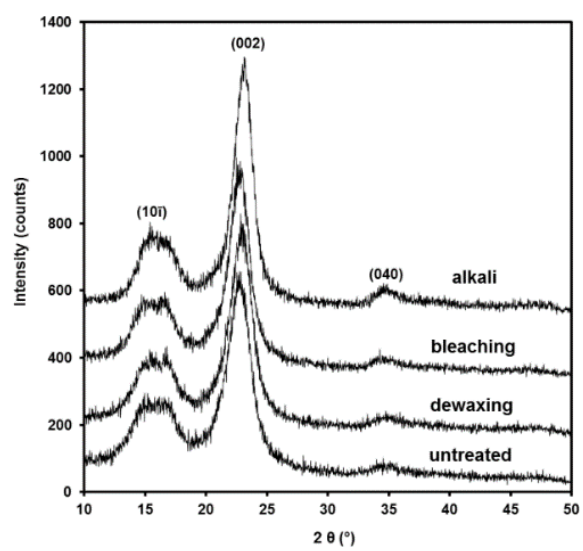

Figure 2. XRD patterns of ramie fiber powder

Table 1. Crystallinity index of ramie fiber powder

\begin{tabular}{cc}
\hline Specimen & $\begin{array}{c}\text { Crystallinity index } \\
(\%)\end{array}$ \\
\hline untreated & 79.75 \\
de-waxing & 85.63 \\
bleaching & 85.50 \\
alkali & 86.68 \\
\hline
\end{tabular}

The thermal stability of the ramie fiber before and after chemical treatments were studied using a thermogravimetric analysis (TGA), and the results are shown in Figure 3. From the figure it can be observed that the four samples (untreated, de-waxing, bleaching, and alkali) exhibited 2 identical 
degradation stages, namely at $30-100{ }^{\circ} \mathrm{C}$ and 200-350 ${ }^{\circ} \mathrm{C}$. The first degradation is related to water evaporation within the fiber (al-Dulaimi and Wanrosli, 2017; Liu et al., 2017). Water evaporation in untreated fiber ended at relatively higher temperature than the treated fiber. This is because the water content absorbed in the untreated fiber was higher than that in the treated one (Ilyas et al., 2018). The reason is that the hemicellulose content in the treated fiber had declined from the chemical treatment. Hemicellulose is a component in fiber that has a high water absorption property. Figure 3 also suggests that the temperature at which $10 \%$ weight loss happened was the highest in the fiber after alkaline treatment, followed by the bleached, de-waxed, and untreated one. This also proved that chemical treatments in ramie fiber can improve the thermal stability. This is in agreement with the FT-IR results that hemicellulose would disappear after alkaline treatment. The second degradation took place at $200-350{ }^{\circ} \mathrm{C}$. This is linked to the decomposition/degradation of the hemicellulose and cellulose components (Ishak et al., 2012).

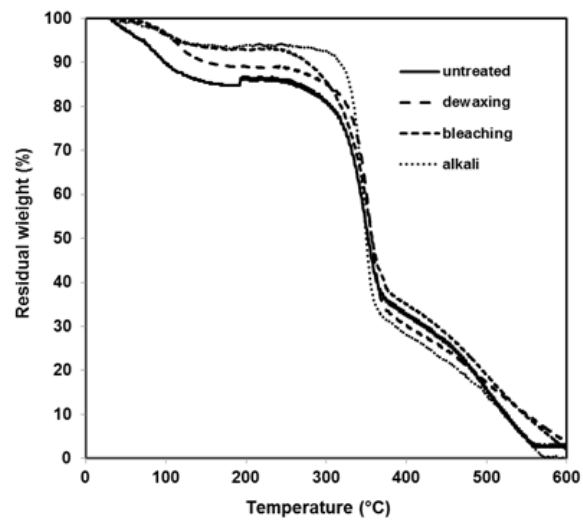

Figure 3. TGA curve of ramie powder

\section{Conclusion}

Based on the FT-IR and XRD analyses results, it can be concluded that chemical treatments (de-waxing, bleaching, and alkali) in ramie fiber had successfully removed hemicellulose component, wax film, and lignin and in turn improve the crystallinity index. Besides, chemical cyrstallinity had been able to improve the thermal stability of ramie fiber.

\section{Acknowledgments}

This research was funded by the 2018 Grant of the Department of Mechanical and Industrial Engineering, Faculty of Engineering, UGM No. 809/H1.17/TMI/LK/2018) and the 2018 Basic Higher Education Distinguished Research Grant (PDUPT) of the Institute for Research and Community Service (LPPM) of UGM No. 110/UN1/DITLIT/DITLIT/LIT/2018). The authors would like to thank Faiz Listyanda and Dimas Abdillah Akbar for the assistance in data collection.

\section{References}

L.K. Kian, M. Jawaid, H. Ariffin, Z. Karim, 2018, Isolation and characterization of nanocrystalline cellulose from rosellederived microcrystalline cellulose, International Journal of Biological Macromolecules, Vol. 114, 54-63.

E. Csiszar, P. Kalic, A. Kobol, E.P. Ferreira, 2016, The effect of low frequency ultrasound on the production and properties of nanocrystalline cellulose suspensions and films, Ultrasonics Sonochemistry, Vol. 31, pp. 473-480.

F.A. Ngwabebhoh, A. Erdem, U. Yildiz, 2018, A design optimization study on synthesized nanocrystalline cellulose, evaluation and surface modification as a potential biomaterial for prospective biomedical applications, International Journal of Biological Macromolecules, Vol. 114, pp. 536-546.

W. Li, J. Yeu, S. Liu, 2012, Preparation of nanocrystalline cellulose via ultrasound and its reinforcement capability for poly (vinyl alcohol) composites, Ultrasonic Sonochemistry, Vol. 19, pp. 479-485.

Y. Habibi, L.A. Lucia, O.J. Rojas, Cellulose nanocrystals: chemistry, selfassembly, and applications, Chem. Rev. 110 (2010) 3479-3500. 
M. Jonoobi, R. Oladi, Y. Davoudpour, K. Oksman, A. Dufresne, Y. Hamzeh, R. Davoodi, 2015, Different preparation methods and properties of nanostructured cellulose from various natural resources and residues: a review, Cellulose, Vol. 22, 935-969.

B.S. L. Brito, F.V. Pereira, J.L. Putaux, B. Jean, 2012, Preparation, morphology and structure of cellulose nanocrystals from bamboo fibers, Cellulose, Vol. 19, pp.1527-1536.

P. Lu, Y.L. Hsieh, 2012, Preparation and characterization of cellulose nanocrystals from rice straw, Carbohydrate Polymers, Vol. 87, pp. 564- 573.

R.A. Ilyas, S.M. Sapuan, M.R. Ishak, 2018, Isolation and characterization of nanocrystalline cellulose from sugar palm fibres (Arenga Pinnata), Carbohydrate Polymers, Vol. 181, pp. 1038-1051.

L. Segal, J.J. Creely, A.E. Martin, C.M. Conrad, 1959, An empirical method for estimating the degree of crystallinity of native cellulose using the X-Ray diffractometer. Textile Research Journal, Vol. 29(10), pp. 786-794.

A. A. Al-Dulaimi, W.D. Wanrosli, 2017, Isolation and Characterization of Nanocrystalline Cellulose from Totally Chlorine Free Oil Palm Empty Fruit Bunch Pulp, Journal of Polymers and the Environment, Vol. 25, pp.192-202.

Z. Liu, X. Li, W. Xie, H. Deng, 2017, Extraction, isolation and Characterization of Nanocrystalline Cellulose from Industrial Kelp (Laminaria Japonica) waste, Carbohydrate Polymers, Vol. 2017, pp. 353-359.

M. R. Ishak, S.M. Sapuan, Z. Leman, M.Z.A.

Rahman, U.M.K. Anwar, 2012, Characterization of sugar palm (Arenga Pinnata) fibres. Journal of Thermal Analysis, and Calorimetry, Vol. 109(2), 981-989. 